are laying down a law which applies to our own criticism of Prof. Walras. We shall therefore forbear to reduce our initial encomium by invidious reservations. When all that could be made are summed and subtracted, there would still remain to Prof. Walras the undoubted glory of an original discovery. He may say of that, as Napoleon of his victories, "Il y a lit du solide que la dent de l'envie ne peut ronger." F. Y. E.

\section{MUSICAL INSTRUMENTS AND THEIR} HOMES.

Musical Instruments and their Homes. By Mary E. Brown and W. Adams Brown. (New York: Dodd, Mead, and Co., I 888.)

THIS work should prove very useful to all who are interested in music and musical instruments. Primarily it professes to be a catalogue of the collection of musical instruments made by Mrs. J. Crosby Brown, of New York; but its value has been greatly augmented by a series of essays on the music and musical instruments of Oriental and savage races. The "catalogue" portion is well illustrated with clever pen-and-ink sketches, which give, for the most part, an excellent idea of the instruments, though they do not exhibit a great amount of detail. A brief description with dimensions, and, where possible, the native name, accompanies each sketch. The catalogue is divided into geographical sections, and at the end of each is added an essay treating of the music of the country from an historical and theoretical point of view, with a general account of the native instruments. Though these essays contain little that is new or original, they nevertheless form extremely useful compilations from a large amount of scattered literature ; the references are full, and the list of authorities is a very representative one.

The sections devoted to China and India are of special interest, as dealing with regions which were the birthplaces of so many of the instruments in use amongst ourselves, changed though these be from their original forms. There seems little doubt, for example, that we owe the harmonium to China, and that instruments played upon with a bow had their original home in India, whither, too, we must refer the original use of "sympathetic strings."

Musical instruments, like all other products of man's handiwork, are subject to the laws of evolution, and each arrived at its present state by gradual stages of improvement. If the genealogies could be all followed back to the earliest stages, all instruments could be referred to such simple original forms as, for example, hollow or solid $\operatorname{logs}$, reeds, or hunters' bows. With the rapid disappearance of the more primitive native instruments, the difficulty of tracing the history of music backwards by means of primitive "survivals" increases year by year. Every effort should be made to collect and place on record these simple forms, as from these we greatly derive our ideas of the "dawn" of music. The magnificent work by Hipkins and Gibb furnishes us with beautiful illustrations of beautiful instruments, but does not deal with the humbler kinds. The illustrations in the present work, therefore, are especially valuable, as the primitive instruments receive equal attention with the more ela- borate. A very common error has crept into the pages of this otherwise excellent work-in the terminology. Nothing is more distinct than instruments of the "oboe" type and those of the "clarionet" type are from each other. These, though somewhat similar in general aspect, belong to different classes-the "double-reed" and the "single-reed" classes respectively; and any relationship must date back to the time when they each probably took their origin from a section of corn-stalk, the one form being sounded through the pinched end of the stalk, and the other through a slit cut in the end, and forming a vibrating or beating tongue. We find, however, in several passages a confusion of these terms. Thus, the Corean, Greek, and Spanish "clarionets," so called, are evidently "oboes," with double reeds for mouth-pieces. Similarly, the "pandeiro" of Madeira, not having a tense membrane, cannot be a "tambourine," however much it looks like one. The "mogugyo," or "wooden fish," of Corea and China, is called a "drum" in one passage (p. 80). But a "drum," too, must have a tense membrane, and an instrument ceases to be one if lacking this addition. The "mogugyo" is really far more closely allied to the "bell" series, though there is no general term which expresses this class of wooden instrument. Such mistakes are, doubtless, mere slips, but they are apt to be misleading.

In the description of savage music it is stated (p. 240) that the Mincopies have no musical instruments. This is not quite true, as they have one, though a simple one, and consisting merely of a hard-wood board, of special shape, which is used for sounding a rhythmical time for dancing. It is used only as a musical instrument, and so illustrates a step in advance of the Australian, who taps with a stick upon his "casting-board" for the same purpose, without employing a separate instrument.

It is to be hoped that other collectors will follow the excellent example of the authors of this work, and publish illustrated catalogues of their collections. We can hardly expect many such beautifully produced "catalogues," but the scientific spirit and easy style of this book might well be a model for others.

\section{OUR BOOK SHELF.}

Heat. By H. G. Madan, M.A., F.C.S. (London: Rivingtons, I 889.)

THIS is an elementary treatise of exceptional merit, combining thoroughly practical work with sound theoretical conclusions. The course of instruction which it comprises has been found suitable by the author, in his capacity as instructor at Eton College, for boys who already have some acquaintance with physiography and elementary dynamics. Mathematical expressions are accordingly used as little as possible, and, when used at all, they are fully explained in ordinary language.

A very large number of experiments - many of them new-are described, and we have the author's assurance that they are all capable of successful performance with moderate skill and care. It is rightly observed that experiments which do not always succeed, even with the greatest care, are altogether unsuitable for young students, as they invariably tend to make them lose confidence in the science.

Particular attention is given throughout to the application of the general laws of heat to the arts and manu- 